\section{Digestion and absorption}

\section{Antral modulation of the transpyloric} flow of liquids in the pig. $\mathrm{CH}$ Malbert, C Mathis (INRA, Station de Recherches Porcines, Équipe Prise d'Aliment et Flux Digestifs, 35590 Saint-Gilles, France)

The fundus is considered as the main determinant for the emptying of liquids in the dog [Kelly (1980) Am J Physiol 239, G71-G76] and the pig [Laplace (1982) In: Physiologie digestive chez le Porc (Laplace JP, Corring T, Rerat A, eds), INRA Publ (Les Colloques de l'INRA No 12) 29-44], while the role of the distal stomach was said to be negligible. However conflicting results suggested that the distal stomach might also play some role in the control of the emptying of liquids [Camilleri et al (1985) Am J Physiol 249, G580-G585; Miller et al (1981) Am J Physiol 241, G403-G415]. Thus the aim of the present work was to investigate the ability of the antrum to generate transpyloric flow pulses in the absence of the fundus.

Acute experiments were performed on 8 Large White female pigs $(36.5 \pm 3.4 \mathrm{~kg})$. Gastropyloro-

\section{Control}

SG terminal Antrum

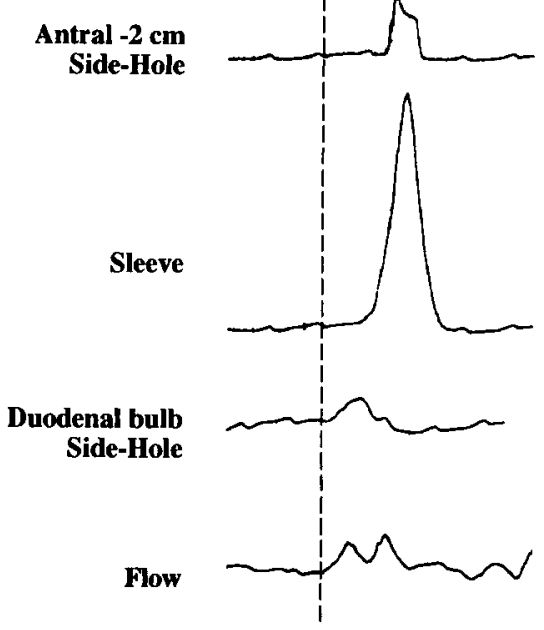

duodenal motility (miniature strain gauges, sleeve manometry, electronically regulated pneumatic barostat) and transpyloric flow (endoluminal flow probe) were simultaneously recorded during the emptying of a liquid acaloric meal (saline infused into the stomach at a constant pressure). Four of the animals underwent functional exclusion of the fundus by surgical creation of a mucosal septum from the lesser to the greater curvature of the stomach [Lind et al (1961) Am J Physiol201, G197-G202].

Major changes of flow pulse characteristics and motility patterns result from fundic exclusion, but the liquid emptying remained pulsatile. The frequency of the flow pulses was decreased after fundic exclusion $(2.8 \pm 0.41$ vs $6.3 \pm 0.41$ pulses $\min ^{-1}, p<0.05$ ) because of an increase of gastroduodenal pressure wave interval (26.2 \pm 1.52 vs $20.7 \pm 0.28 \mathrm{~s}, p<0.05$ ) which might be related to the large amount of fluid present in the antrum. Flow pulses occurred simultaneously with antral and pyloric waves whereas they occurred $2.8 \pm 0.77 \mathrm{~s}$ before antropyloric waves in intact pigs (fig 1). The amplitude of the antropyloric waves and the basal pressures at the gas-
Proximal stomach exclusion

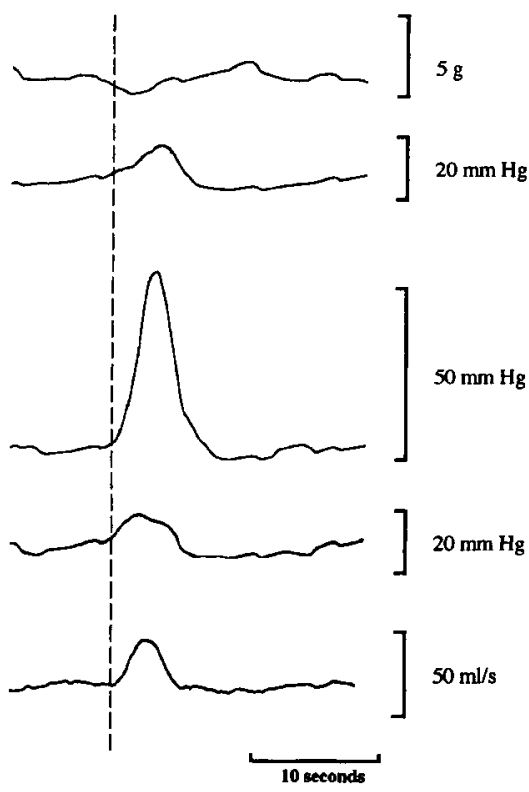

Fig 1. Effects of proximal stomach exclusion. The motility was reduced in the terminal antrum, the frequency of the pylonic (sleeve) pressure events decreased and the characteristics of the transpyloric flow pulses were altered (CH Malbert, $\mathrm{C}$ Mathis). 
troduodenal junction were reduced. The change in the temporal relationship between pressure events and flow pulses was the causative factor for a decrease in resistance $(6.1 \pm 0.21$ vs $14.9 \pm$ $0.54 \mathrm{ml}^{\bullet} \mathrm{s}^{-1} \bullet \mathrm{mmHg}$ after fundic exclusion and in intact pigs respectively, $p<0.05$ ).

The resulting decrease in the pyloric resistance was responsible for larger stroke volume pulses ( $2.3 \pm 0.10$ vs $0.3 \pm 0.01 \mathrm{ml}, p<0.05)$. Moreover backflow and non-pulsatile flow, typical features in intact animals, were not recorded after fundic exclusion. The final score of liquid emptying after fundic exclusion did not differ from control, though obtained in a different way by summing larger but less frequent flow pulses.

In conclusion, even when fundus action is prevented, the antropyloric area can modulate the gastric emptying of liquids by means of adjusted motility of the terminal antrum and of pyloric resistance.
Vagal control of the transpyloric flow and pyloric resistance in the pig. $\mathrm{CH}$ Malbert, C Mathis, JP Laplace (INRA, Station de Recherches Porcines, Équipe Prise d'Aliment et Flux Digestifs, 35590 Saint-Gilles, France)

Transpyloric flow and antropyloroduodenal resistance in the dog have been shown to vary simultaneously and in parallel [Malbert and Ruckebusch (1991) Am J Physiol 260, G653-G657; Malbert et al (1992) Am J Physiol 263, G202G208]. As flow-sensing receptors have been found in the duodenum of the cat [Malbert and Leitner (1993) Am J Physiol 265, G310-G313], it can be assumed that the pyloric resistance varies as a function of the digesta flow into the duodenum. Therefore, we hypothesized that pyloric resistance is controlled through a vagal reflex, the afferent part of which originates from

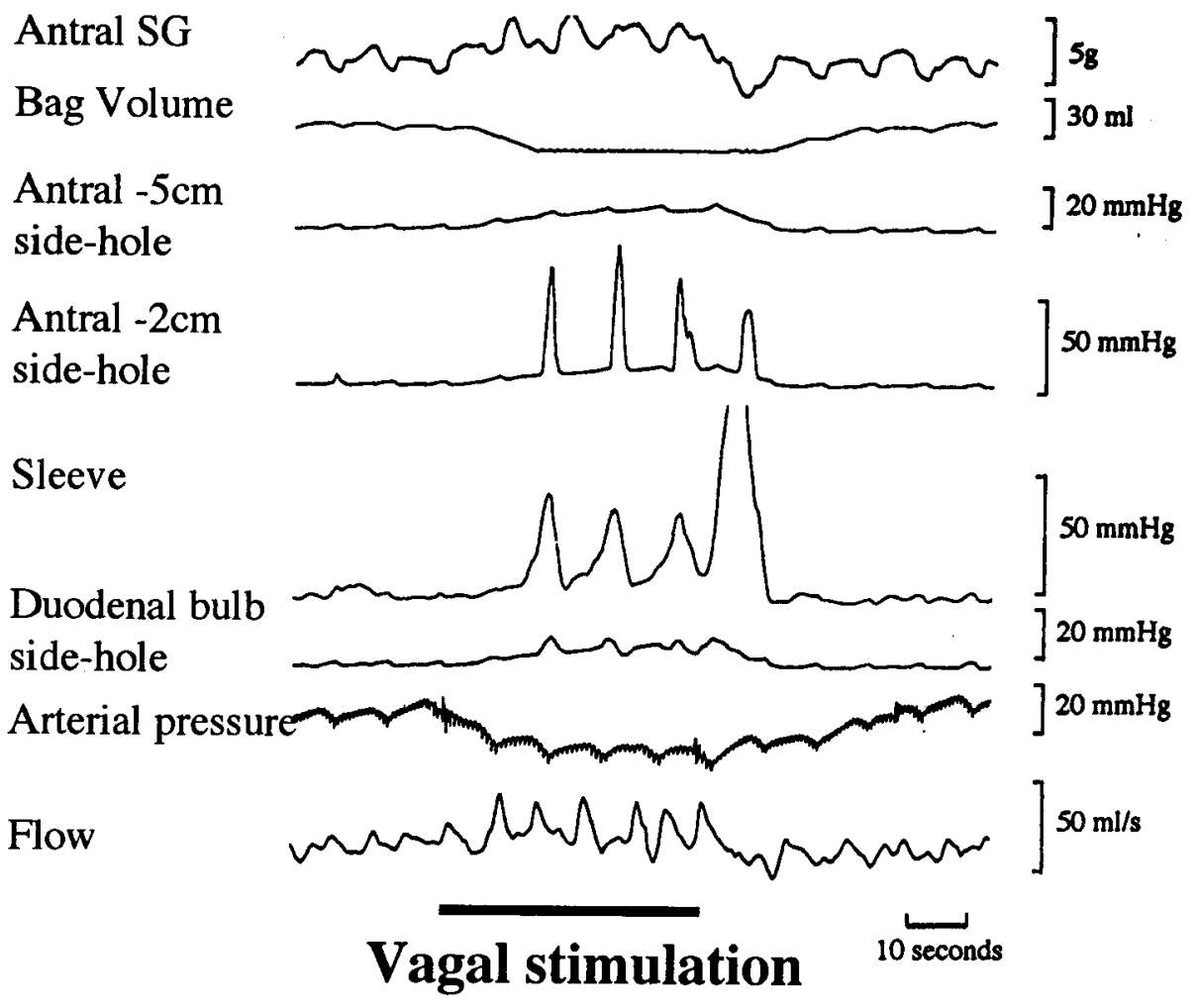

Fig 1. Effects of electrical stimulation ( 20 volts, $5 \mathrm{H} 2,1 \mu \mathrm{s}$ ) of the peripheral end of the left-cervical vagus on antro-pyloro-duodenal motor activity and transpyloric flow. ( $\mathrm{CH}$ Malbert et al) 